
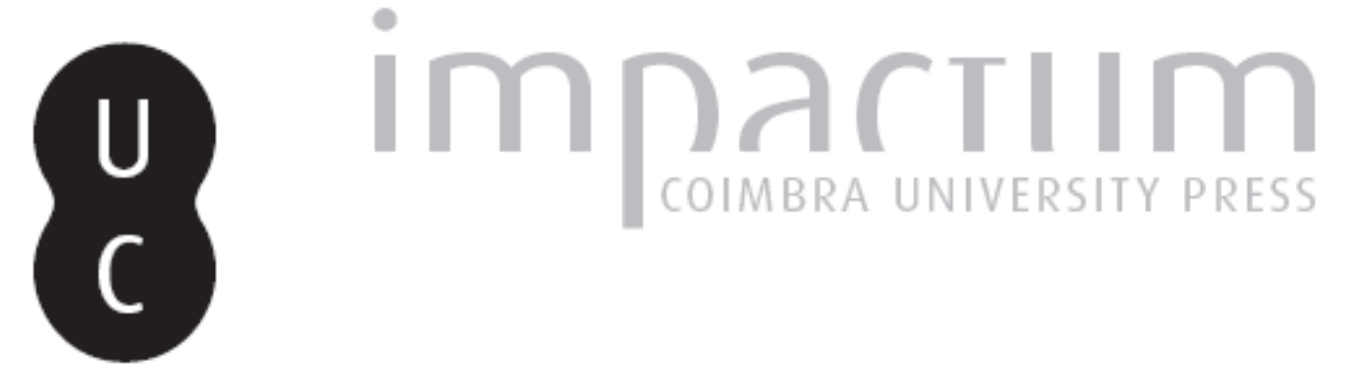

\title{
A ilha de calor e a umidade relativa em Aracaju-Sergipe (Brasil): intensidade e comportamento intradiurno
}

Autor(es): $\quad$ Anjos, Max Wendell Batista dos; Ganho, Nuno; Araújo, Hélio Mário de

Publicado por: Imprensa da Universidade de Coimbra

URL persistente:

URI:http://hdl.handle.net/10316.2/36884

DOI:

DOI:http://dx.doi.org/10.14195/0871-1623_33_4

Accessed : $\quad$ 26-Apr-2023 08:49:30

A navegação consulta e descarregamento dos títulos inseridos nas Bibliotecas Digitais UC Digitalis, UC Pombalina e UC Impactum, pressupõem a aceitação plena e sem reservas dos Termos e Condições de Uso destas Bibliotecas Digitais, disponíveis em https://digitalis.uc.pt/pt-pt/termos.

Conforme exposto nos referidos Termos e Condições de Uso, o descarregamento de títulos de acesso restrito requer uma licença válida de autorização devendo o utilizador aceder ao(s) documento(s) a partir de um endereço de IP da instituição detentora da supramencionada licença.

Ao utilizador é apenas permitido o descarregamento para uso pessoal, pelo que o emprego do(s) título(s) descarregado(s) para outro fim, designadamente comercial, carece de autorização do respetivo autor ou editor da obra.

Na medida em que todas as obras da UC Digitalis se encontram protegidas pelo Código do Direito de Autor e Direitos Conexos e demais legislação aplicável, toda a cópia, parcial ou total, deste documento, nos casos em que é legalmente admitida, deverá conter ou fazer-se acompanhar por este aviso.

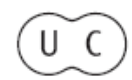




\section{Cadernos de Geografia}
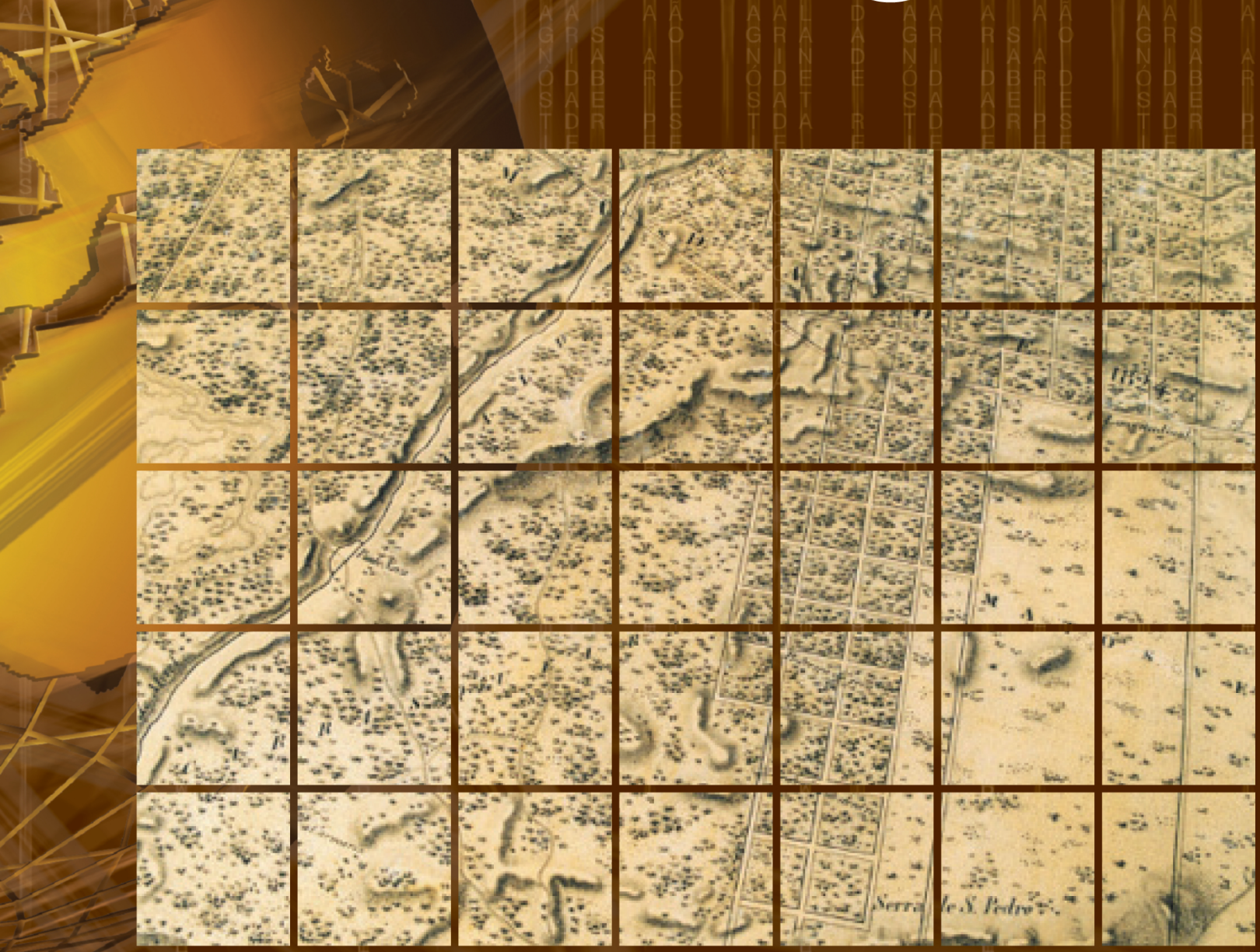

№ 33 - 2014

Imprensa da Universidade de Coimbra Faculdade de Letras | Universidade de Coimbra 


\title{
A ilha de calor e a umidade relativa em Aracaju-Sergipe (Brasil). Intensidade e comportamento intradiurno \\ The heat island and relative humidity in Aracaju-Sergipe (Brazil): intensity and behavior itra-daytime.
}

\author{
Max Wendell Batista dos Anjos \\ Centro de Estudos Geográficos da Universidade de Lisboa. \\ maxgeoline@hotmail.com
}

\author{
Nuno Ganho \\ Departamento de Geografia. Faculdade de Letras. Universidade de Coimbra. \\ nganho@netvisao.pt
}

\section{Hélio Mário de Araújo}

Departamento de Geografia da Universidade Federal de Sergipe.

heliomarioaraujo@yahoo.com.br

\section{Resumo:}

Este trabalho tem por objetivo analisar os contrastes topoclimáticos no espaço urbano e periurbano da cidade de Aracaju. Isto foi possível mediante o confronto dos dados de temperatura e umidade relativa entre as estações meteorológicas urbanas com a estação meteorológica de caráter mais periurbano. As frequências relativas de ocorrência de diferenças de temperatura máxima maiores que zero $(\%>0)$, superaram os $96 \%$ no centro cidade e com frequências de $100 \%$ durante os finais da manhã até parte da noite. Além disso, a estação do centro registrou em média $3,6^{\circ} \mathrm{C}$ maior que a estação do aeroporto. Os resultados indicam evidências significativas das diferenças térmica e higrométrica entre a área urbana e periurbana, o que leva a fortes indícios de ocorrência da ilha de calor em Aracaju.

Palavras-chave: Clima Urbano. Ilha de Calor Urbano. Aracaju.

\section{Abstract:}

This paper goal to analyse the topoclimatic contrasts in urban and suburban space in Aracaju city. The result was established by comparing the data of temperature and relative humidity from urban weather stations with the data from the weather station, which are of a more suburban character. The relative frequency of occurrence of differences in maximum temperature higher than zero $(\%>0)$, exceeding it in $96 \%$ of the times in the city centre and about $100 \%$ frequency during late morning until evening. Furthermore, the center station recorded $3,6^{\circ} \mathrm{C}$ on average greater than the airport station. The results indicts significant evidence of the thermal and hygrometric differences between the urban and periurban area, leading to substantial evidence of the occurrence of heat islands in the mentioned in Aracaju.

Keywords: Urban Climate. Urban Heat Island. Aracaju. 


\section{Introdução}

Estima-se que, de um total de 5,5 milhões em 1993, a população mundial alcance os 8,2 milhões em 2025, com uma proporção de população urbana que subirá de 40 a $50 \%$ durante o mesmo período. Isto é, a partir do próximo século, a maior parte da população do mundo viverá e trabalhará sob influências climáticas urbanas.

Um dos obstáculos ao desenvolvimento adequado das cidades brasileiras é a crescente degradação do ambiente urbano e da qualidade de vida. A paisagem natural é extremamente modificada na cidade, para dar lugar à concentração de casas, instalações industriais, adensamento populacional e pavimentação asfáltica. Com efeito, essa alteração, por via descontrolada do uso do solo, provoca alterações climáticas significativas, como por exemplo, o fenômeno da Itha de Calor (OKE, 1987; GANHO, 1999), largamente estudado nas mais diversas cidades do mundo sob diferente contexto natural, social e cultural (ARNFIELD, 2003).

O desenvolvimento urbano de Aracaju não foge à regra da maioria das cidades brasileiras, que seguem a lógica de reprodução do capital, produzindo espaços acentuadamente diferenciados, sob o ponto de vista socioeconômico e ambiental. 0 contexto de degradação ambiental em que se encontra a referida cidade foi a base inicial para o desenvolvimento deste trabatho que tem como objetivo análisar os contrastes térmicos e higrométricos, à escala topoclimática, no espaço urbano e periurbano na cidade de Aracaju.

A escolha da cidade de Aracaju vai aquém de pretensões pessoais ou emocionais, posto que, ela própria, pela sua condição natural e social, constitui um ambiente favorável ao estudo de clima urbano (AnJos, 2012;2014). Localizada na região Nordeste do Brasil, Aracaju foi projetada para ser a capital do estado de Sergipe e hoje conta com mais de meio milhão de habitantes (IBGE, 2012), seguindo o padrão das cidades de porte médio brasileiras. Está situada no litoral, conhecida como a região da Zona da Mata, cuja posição, em latitudes baixas, confere um papel muito importante no condicionamento climático da cidade. Compreende uma área de $181,8 \mathrm{~km}^{2}$ e delimita-se pelas coordenadas de $10^{\circ} 51^{\prime}$ $45^{\prime \prime}$ e $11^{\circ} 07^{\prime} 49^{\prime}$ de latitude sul e de $37^{\circ} 02^{\prime} 02^{\prime \prime}$ e $37^{\circ}$ 09' 04' de longitude oeste, que a posiciona completamente na zona intertropical. 0 relevo aracajuano é pouco expressivo, as cotas altimétricas variam na ordem de dois a oito metros acima do nível do mar. Somente na parte oeste e, sobretudo ao norte, as cotas se elevam em morros e colinas numa altitude de aproximadamente $100 \mathrm{~m}$, representando a área mais elevada da cidade. 0 município possui uma densa rede hidrografia, nomeadamente as bacias hidrográficas do Rio Sergipe e do Rio Vaza Barris além de uma série de riachos (Figura 1).

As condições meteorológicas de Aracaju dependem fundamentalmente dos centros de ação, das correntes atmosféricas perturbadas, das influências conjugadas do oceano Atlântico e, sobretudo, do estuário do rio Sergipe, além da possível atuação persistente da circulação de brisas; estas associadas à ausência de obstáculos que se interponham entre a cidade e o mar, revestem-se de extrema importância na compreensão da sua dinâmica topoclimática. Tal como a ocupação urbana do solo cria um campo termohigrométrico específico, concorrendo para a ocorrência de temperaturas mais elevadas do que no espaço não urbano periférico, que constitui a chamada ilha de calor, normalmente associada a menores valores de humidade relativa.

No que diz respeito à marcha estacional da precipitação e aos sistemas de circulação atmosférica, o clima de Aracaju segundo classificação climática de NIMER (1972) é considerado Tropical Úmido com duração do período seco de três meses. 0 máximo de precipitação ocorre em simultâneo com uma ligeira diminuição das temperaturas médias e decorre da influência da Zona de Convergência Intertropical, de Ondas de Este ou de intrusões de ar polar tropicalizado, criando um ritmo termopluviométrico com afinidades ao dos climas mediterrâneos extratropoicais, podendo, por isso, ser também denominado clima mediterrâneo quente" (op. cit.: 42).

As temperaturas médias anuais e mensais são elevadas, apresentando variações entre $27^{\circ} \mathrm{C}$ e $25^{\circ} \mathrm{C}$, de acordo com os dados referentes ao período 1961-2010 (INMET, 2012). Essa desprezível variação anual pode ser explicada pelas médias elevadas em todos os meses que, devido à latitude da cidade, concorre para uma baixa amplitude térmica anual, variando de 2 a $3^{\circ} \mathrm{C}$. A umidade relativa ronda, em média, os $70 \%$, para qualquer mês e em qualquer dos anos considerados (1961-2010), jus tificada pela posição da cidade próxima ao litoral e à inexistência de obstáculos à penetração do ar úmido do oceano Atlântico. A cidade é, ainda, percorrida por vários corpos d'água o que alimenta, de certa forma, esses persistentes índices de umidade relativa.

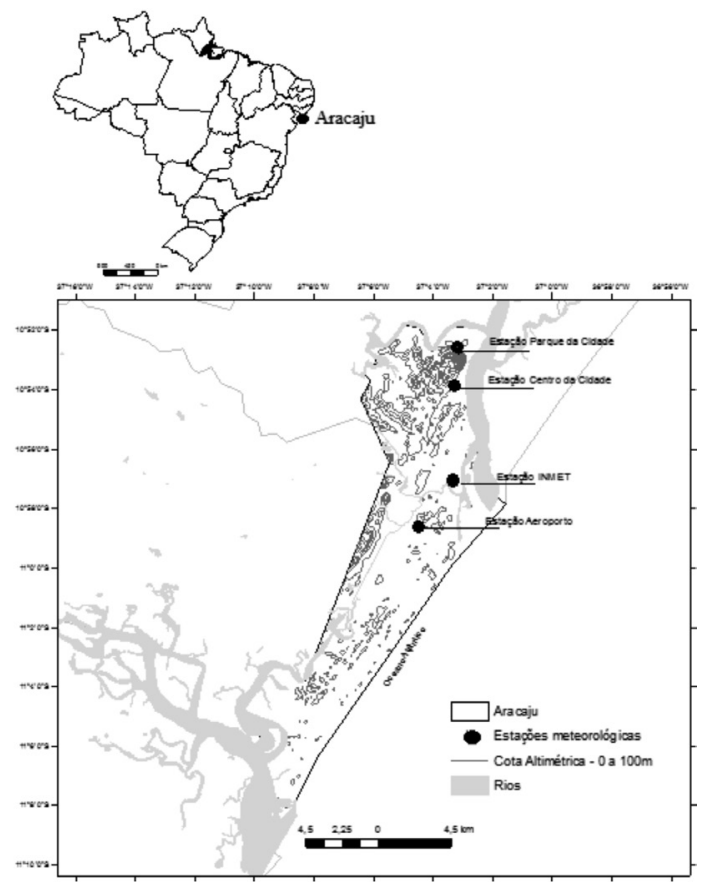

Figura 1

Esboço da localização geográfica da área em estudo e estações meteorológicas.

Fonte: Base cartográfica -Altas Digital SRH, 2012. 


\section{Metodologia}

\subsection{Localização e representatividade espacial das estações meteorológicas}

As observações meteorológicas padrão têm por finalidade expressar o comportamento das variáveis atmosféricas à escala regional, mas ao mesmo tempo, têm uma dificuldade em representar as áreas urbanas como um todo. Isto porque as cidades crescem em diferentes contextos topográficos que geram diferentes condições topoclimáticas. A fim de abarcar esses contrastes climáticos existentes na área urbana e adjacências, instalaram-se duas estações meteorológicas urbanas, do tipo Weatherwise Instruments Model-WS1080-E.U.A, a 1,5m do solo. O presente estudo foi complementado com outras duas estações padronizadas, nomeadamente a do Instituto Nacional de Meteorologia e da INFRAERO

A escolha dos pontos de medição através das estações meteorológicas urbanas deu-se por forma a contemplar, segundo MonTEIRo (1990:.6): caráter geo-ecológico do sítio sobre o qual se assenta a cidade, expondo as unidades morfológicas que nele se distinguem; a estrutura (morfologia+funções) urbana, tomada não como superposição, mas como "integração" ao primitivo geo-ecológico; o dinamismo urbano representado por várias funções em sua morfologia: fluxos de tráfego de veículos, atividade industrial e entre outros.

A primeira estação urbana localiza-se no centro da cidade (CC), caracterizada pela forte densidade de ocupação, solos impermeáveis, vegetação esparsa (as áreas com vegetação mais densa estão restritas às praças), ladeada de edifícios com até três pavimentos, com exceção de alguns acima de três pavimentos distribuídos de forma isolada. 0 uso do solo é predominantemente comercial e serviços, de intenso fluxo de pessoas e veículos. A segunda estação urbana localiza-se na área mais elevada, mais especificamente na reserva florestal Parque da Cidade (PC), numa altitude $100 \mathrm{~m}$ ao norte da cidade. A área é constituída praticamente de vegetação densa com porte arbóreo e fraca densidade de ocupação.

A estação padrão do Instituto Nacional de Meteorologia (INMET) opera desde 1910, é a responsável em fornecer dados meteorológicos e previsões de tempo detalhadas aos cidadãos. A estação do INMET segue os padrões estabelecidos pela OMM (Organização Mundial de Meteorologia). Atualmente ocupa uma área predominantemente residencial e com edifícios na sua parte leste, vegetação esparsa de porte médio a pequeno. A estação da INFRAERO (INFRA) localiza-se no Aeroporto Santa Maria, é a que melhor representa a situação periurbana nesse estudo, e se caracteriza pela vegetação esparsa de porte médio e pequeno, fraca ocultação do horizonte e uso do solo tipicamente residencial.

A localização e a síntese das informações de todas as estações utilizadas neste estudo podem ser visualizadas na Figura 1 e Quadro I, respectivamente.
Quadro I

Aracaju - Estações meteorológicas do estudo-síntese das informações.

\begin{tabular}{|c|c|c|c|c|c|}
\hline \multirow{2}{*}{$\begin{array}{c}\text { Estações } \\
\text { Meteoro- } \\
\text { lógicas }\end{array}$} & \multirow{2}{*}{$\begin{array}{l}\text { Coordena- } \\
\text { das geo- } \\
\text { gráficas }\end{array}$} & \multirow{2}{*}{ Altitude } & \multicolumn{2}{|c|}{$\begin{array}{c}\text { Distância } \\
\text { em relação }\end{array}$} & \multirow{2}{*}{$\begin{array}{l}\text { Características } \\
\text { próximas do local }\end{array}$} \\
\hline & & & $\begin{array}{c}\text { Rio } \\
\text { (Sergipe) }\end{array}$ & Mar & \\
\hline $\begin{array}{c}\text { PC } \\
\text { (Parque } \\
\text { da cidade) }\end{array}$ & $\begin{array}{l}10^{\circ} 52^{\prime} \\
52.5^{\prime \prime} \mathrm{S} \\
37^{\circ} 03^{\prime} \\
11.1^{\prime \prime} \mathrm{W}\end{array}$ & $100 \mathrm{~m}$ & $560 \mathrm{~m}$ & $5.6 \mathrm{~km}$ & $\begin{array}{l}\text { Esquadrão da } \\
\text { Polícia Montada } \\
\text { (EPmon) com } \\
\text { sede no Parque da } \\
\text { Cidade. Grande } \\
\text { permeabilidade } \\
\text { do solo. Grande } \\
\text { presença de ve- } \\
\text { getação de porte } \\
\text { arbóreo, médio } \\
\text { Sky View Factor. }\end{array}$ \\
\hline $\begin{array}{c}\text { CC } \\
\text { (Centro da } \\
\text { cidade) }\end{array}$ & $\begin{array}{l}10^{\circ} 53^{\prime} \\
54.9^{\prime \prime} \mathrm{S} \\
37^{\circ} 03^{\prime} \\
52^{\prime \prime} \mathrm{W}\end{array}$ & $12 m$ & $660 \mathrm{~m}$ & $5 \mathrm{~km}$ & $\begin{array}{l}\text { Rua Capela (es- } \\
\text { tacionamento do } \\
\text { supermercado } \\
\text { Bompreço). } \\
\text { Orientação da rua } \\
\text { norte-sul. Elevada } \\
\text { impermeabilização } \\
\text { do solo; vegetação } \\
\text { Esparsa. Intenso } \\
\text { fluxo de pessoas e } \\
\text { veículos, médio e } \\
\text { elevado Sky View } \\
\text { Factor. }\end{array}$ \\
\hline $\begin{array}{c}\text { INMET } \\
\text { (Instituto } \\
\text { Nacional } \\
\text { de Meteo- } \\
\text { rologia) }\end{array}$ & $\begin{array}{l}10.95 \\
00^{\circ} \mathrm{S} \\
37.05 \\
00^{\circ} \mathrm{W}\end{array}$ & $4.72 \mathrm{~m}$ & $1 \mathrm{~km}$ & $3 \mathrm{~km}$ & $\begin{array}{l}\text { Próximo ao estuá- } \\
\text { rio do rio Sergipe, } \\
\text { nomeadamente na } \\
\text { margem direita. } \\
\text { Solos permeáveis } \\
\text { (exceção das } \\
\text { ruas, avenidas } \\
\text { e condomínios). } \\
\text { Vegetação esparsa } \\
\text { de porte médio e } \\
\text { pequeno. Baixo } \\
\text { Sky View Factor. }\end{array}$ \\
\hline $\begin{array}{c}\text { INFRA } \\
\text { (Infraero) }\end{array}$ & $\begin{array}{c}10^{\circ} 59 \\
\text { '3.54"S } \\
37^{\circ} 5 \text { '6. } \\
30^{\prime \prime} \mathrm{W}\end{array}$ & $9 \mathrm{~m}$ & --- & $3 \mathrm{~km}$ & $\begin{array}{l}\text { Aeroporto Santa } \\
\text { Maria com fraca } \\
\text { densidade de } \\
\text { ocupação. Solos } \\
\text { permeáveis; } \\
\text { vegetação esparsa } \\
\text { de porte médio e } \\
\text { pequeno. Baixo } \\
\text { Sky View Factor. }\end{array}$ \\
\hline
\end{tabular}

Fonte: AnJos, 2012

\subsection{Levantamento e tratamento dos dados}

Foram levantados dados horários de temperatura (T0 a T23) e umidade relativa (U0 a U23) no período diurno e noturno entre os dias 14 de janeiro e 19 de março de 2012, correspondendo a 66 dias de observação ${ }^{1}$, exceto para a estação CC que operou no período entre 14 de janeiro a 12 de fevereiro de 2012 , totalizando 30 dias. 0 segmento temporal do estudo compreende a estação de verão estendendo-se para o início de outono devido o caráter estival do mês de março, por se tratar do período estatísticamente mais seco e no qual, por isso, os contrastes térmohigrométricos espaciais são mais expressivos.

Considerou-se sempre a hora sinótica (UTCTempo Universal Coordenado) que corresponde a 3

Em função de problemas técnicos na estação CC, os dados entre os dias 11 e 27 de fevereiro de 2012 não foram incluídos na análise. 
horas a mais em relação à hora local. A diferença do horário UTC para a hora local permaneceu durante todo segmento temporal do estudo, uma vez que atualmente o estado de Sergipe não tem aderido ao horário de verão. Em seguida, efetuaram-se as correções do horário local das estações Parque da Cidade (PC), Centro da Cidade (CC) e Infraero (INFRA) para a hora sinótica do Instituto Nacional de Meteorologia (INMET).

Uma vez corrigidos os horários, procedeu-se ao tratamento estatístico dos dados a fim de verificar os contrastes térmicos e higrométricos entre as estações referenciadas. Para tal, utilizou-se a metodologia desenvolvida por GANHO (1995, 1998, 2000), na qual se comparam os dados das estações localizadas no espaço urbano com os do espaço periurbano ou rural. Como a Prefeitura Municipal de Aracaju não reconhece a existência de uma zonal rural no seu interior do seu espaço, optou-se por comparar os dados da estação que mais caracterizasse a área periurbana, neste caso a INFRA, com os dados das demais estações. Sendo assim, calcularam-se as diferenças INMET-INFRA, CC-INFRA e PC-INFRA de temperaturas horárias ( $\triangle \mathrm{T} 0$ a $\triangle T 23)$, e INMET-INFRA, CC-INFRA e PC-INFRA das umidades relativas horárias ( $\triangle \mathrm{U} 0$ a $\Delta \mathrm{U} 23)$. Logo depois, definiram-se 24 séries de cada variável correspondentes a cada par de estações comparadas.

Esse fato permitiu analisar vários parâmetros estatísticos, tais como: as médias e as medianas de temperatura e umidade relativa ( $\Delta$ Tmed e $\Delta$ Umed); as temperaturas máximas e mínimas $(\Delta T \max$ e $\Delta T \operatorname{Tmin})$ e umidade relativa mínima $(\Delta \mathrm{Umin})$; a frequência relativa de ocorrência de valores positivos, nulos ou negativos de temperatura e de umidade relativa e os valores extremos: máximos e mínimos. Além desses parâmetros, calculou-se o desvio padrão a fim de verificar a variabilidade térmica e higrométrica.

Para além dos parâmetros estatísticos referidos, efetuou-se o cálculo das taxas de resfriamento e aquecimento, posto que, as cidades, em tese, apresentam uma maior inércia térmica em relação às áreas adjacentes (OKE, 1982). Assim, segundo o procedimento utilizado por GANHO $(1995,1998,2000)$ determinou-se, para cada estação meteorológica, a variação térmica inter-horária através da diferença entre a temperatura observada a uma dada hora e a temperatura observada à hora imediatamente anterior $\left(T_{h-} T_{h-1}\right)$. Para cada uma das séries correspondentes às 24 variáveis assim obtidas (de $T_{1-0}$ a $\mathrm{T}_{24-23}$ ) calcularam-se as médias, chegando-se assim às taxas médias de aquecimento ou resfriamento horário de cada estação.

Os contrastes térmicos e higrométricos à escala topoclimática definidos a partir do confronto entre as estações meteorológicas PC, CC, INMET com a INFRA e as áreas por elas representadas, foram analisadas, com propriedade, embora em sentido lato, como sinônimo da "ilha de calor" urbano de Aracaju para os contrastes térmicos e sinônimo de "ilha de secura" para os de umidade relativa, como sugere GANHO (1998).

\section{Resultados e discussões}

\subsection{Análise comportamental da temperatura}

\subsubsection{Temperaturas máximas e mínimas diárias em relação aos valores absolutos}

A síntese dos parâmetros estatísticos apresentados no Quadro II revelou significativos contrastes térmicos no que pese às séries de diferenças de temperaturas máximas e de temperaturas mínimas diárias, entre cada par de estações comparadas, obtidos para os 66 dias de observação (30 dias no caso da estação do Centro - CC).

Quadro II

Aracaju - Parâmetros estatísticos (tendência central, dispersão, extremos e frequência de ocorrência de valores positivos e nulos ou negativos) das séries horárias de diferenças de temperatura máxima $(\Delta T \max )$ e mínima $(\Delta T \min )$

\begin{tabular}{|c|c|c|c|c|c|c|}
\hline \multirow{2}{*}{} & \multicolumn{3}{|c|}{$\Delta$ Tmax $\left({ }^{\circ} \mathrm{C}\right)$} & \multicolumn{3}{c|}{$\Delta$ Tmin $\left({ }^{\circ} \mathrm{C}\right)$} \\
\cline { 2 - 7 } & $\begin{array}{c}\text { INMET- } \\
\text {-INFRA }\end{array}$ & $\begin{array}{c}\text { CC- } \\
\text {-INFRA }\end{array}$ & $\begin{array}{c}\text { PC- } \\
\text {-INFRA }\end{array}$ & $\begin{array}{c}\text { INMET- } \\
\text {-INFRA }\end{array}$ & $\begin{array}{c}\text { CC- } \\
\text {-INFRA }\end{array}$ & $\begin{array}{c}\text { PC- } \\
\text {-INFRA }\end{array}$ \\
\hline Média & -0.6 & 2.6 & -1.6 & 0.1 & 0.5 & -0.3 \\
\hline Mediana & -0.4 & 2.9 & -1.5 & 0 & 0.5 & -0.3 \\
\hline $\begin{array}{c}\text { Desv. } \\
\text { Padrão }\end{array}$ & 1.3 & 1.5 & 1.2 & 1.5 & 0.8 & 1.4 \\
\hline Máximo & 1.8 & 5 & 0.5 & 2.7 & 1.8 & 3.3 \\
\hline Mínimo & -5.1 & -3.2 & -6 & -2.6 & -0.9 & -3 \\
\hline$\%>0$ & 32.3 & 96.4 & 4.6 & 49.2 & 75.0 & 41.5 \\
\hline$\% \leq 0$ & 67.7 & 3.6 & 95.4 & 50.8 & 25.0 & 58.5 \\
\hline
\end{tabular}

Fonte: Observações em campo (CC e PC), INMET e INFRAERO.

Os contrastes de temperatura máxima foram mais evidentes para CC-INFRA por apresentar a maior média de $2.6^{\circ} \mathrm{C}$ em relação aos demais: $-1.6^{\circ} \mathrm{C}$ para PC-INFRA e $-0.6^{\circ} \mathrm{C}$ para INMET-INFRA. Esse valor positivo quer dizer que $\mathrm{CC}$ e áreas por ela representadas, têm temperaturas máximas mais elevadas do que a periferia. A mediana se mostrou também maior para CC-INFRA $\left(2.9^{\circ} \mathrm{C}\right)$ em relação ao par INMET-INFRA $\left(-0.4^{\circ} \mathrm{C}\right)$ e PC-INFRA $\left(-1.5^{\circ} \mathrm{C}\right) .0$ par CC-INFRA continuou a sobressair dos demais, acusando a maior variabilidade térmica $\left(1.5^{\circ} \mathrm{C}\right)$ seguido por INMET-INFRA $\left(1.3^{\circ} \mathrm{C}\right)$ e por último PC-INFRA $\left(1.2^{\circ} \mathrm{C}\right)$. 0 maior contraste extremo de temperatura máxima foi encontrado no centro da cidade, representada pela CC, a qual acusou uma diferença de $5^{\circ} \mathrm{C}$ em relação à periferia (INFRA), uma diferença bem maior da outra estação localizada em área urbana, representada pela INMET com $1.8^{\circ} \mathrm{C}$ e mais ainda para a estação do espaço verde, representada pela $\mathrm{PC}$ com $0.5^{\circ} \mathrm{C}$. 0 extremo mínimo de temperatura máxima colocou, ao contrário do extremo máximo, o par PC-INFRA com o maior valor de $-6^{\circ} \mathrm{C}$ seguido por INMET-INFRA com $-5.1^{\circ} \mathrm{C}$ e o menor valor ao par CC-INFRA com $-3.2^{\circ} \mathrm{C}$.

As frequências relativas de ocorrência de diferenças de temperatura máxima maiores que zero ajudaram a comprovar, de fato, a existência de significativos contrastes térmicos em Aracaju, sobretudo, quando se observou a frequência de $96.4 \%$ dos dias analisados para CC-INFRA em que a temperatura no centro da cidade foi superior à do espaço periurbano. 
Já para INMET-INFRA, embora localizada em área urbana, mas pelo fato de receber influência amenizadora do estuário do rio Sergipe, correspondem-lhe frequências relativas de apenas $32,3 \%$ do período analisado. Menor ainda é para PC-INFRA com apenas $4.6 \%$, o que já era esperado dado sua localização em um espaço verde. No tocante aos contrates de diferenças das temperaturas mínimas, os parâmetros se mostraram diversos dos da máxima. A média e mediana foram iguais para os pares CC-INFRA com $0.5^{\circ} \mathrm{C}$ e PC-INFRA com $-0.3^{\circ} \mathrm{C}$, exceto para INMET-INFRA com $0^{\circ} \mathrm{C}$. $\mathrm{O}$ valor de $1.5^{\circ} \mathrm{C}$ de desvio-padrão confere ao INMET-INFRA a maior variabilidade térmica, logo seguido por PC-INFRA com $1.4^{\circ} \mathrm{C}$, valores bem superiores ao CC-INFRA de apenas $0.8^{\circ} \mathrm{C}$. As causas das maiores diferenças de dia do que de noite tem a ver com a conjugação dos efeitos de sombra/exposição relativamente à radiação solar directa e de abrigo/exposição relativamente aos fluxos canalizados pelo ar úmido do rio e mar no interior do tecido urbano.

Comparativamente às temperaturas máximas, os papéis dos extremos de temperatura mínima se invertem tanto para o máximo como para o mínimo valor. Para o primeiro, tem-se o INMET-INFRA $\left(5.7^{\circ} \mathrm{C}\right)$, o PC-INFRA $\left(3.3^{\circ} \mathrm{C}\right)$ e CC-INFRA $\left(1.8^{\circ} \mathrm{C}\right)$, enquanto para o segundo tem-se INMET- INFRA com -2.6, PC-INFRA com $-3^{\circ} \mathrm{C}$ e $-0.9^{\circ} \mathrm{C}$ para CC-INFRA. Isso tem a ver com a redução do fluxo irradiativo e reforço da contra-irradiação nocturna nos espaços com maior índice de ocupação do solo.

\subsubsection{Comportamento intradiurno}

\subsubsection{Frequência de ocorrência}

Com relação à frequência de ocorrência inter-horária de diferenças de temperatura superiores a $0^{\circ} \mathrm{C}$, como indicativo de ilha de calor, notou-se, claramente, um comportamento intradiurno diverso entre os pares analisados (Figura 2). Para INMET-INFRA em qualquer hora do dia não ultrapassaram os $50 \%$, exceto às primeiras horas da manhã $(9-11 \mathrm{~h})$, ao contrário do CC-INFRA que apenas às $5 \mathrm{~h}$ registrou valores abaixo dos $50 \%$, porque durante os finais da manhã até princípios da noite (10h-19h), os valores se situaram por volta dos $100 \%$. Para PC-INFRA os valores são superiores aos $50 \%$ somente no início da noite, de madrugada e se estendendo até o período da manhã (20h-9h).

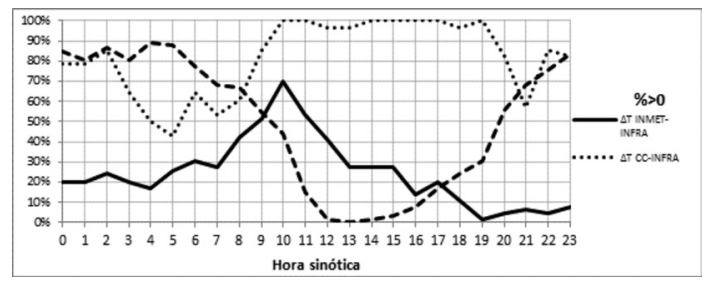

Figura 2

Aracaju - Variação intradiurna da frequência de ocorrência de diferenças de temperatura superiores a $0^{\circ} \mathrm{C}\left(\triangle T>0^{\circ} \mathrm{C}\right)$.

Fonte: Observações em campo (CC e PC), INMET e INFRAERO.
Atente-se para o fato de que nas primeiras horas do dia (0-8h) o Parque da Cidade (PC), esteve tendencialmente mais quente não só do que a periferia (INFRA), como inclusive do que o Centro da Cidade (CC). Mais do que ao efeito de sombra urbano no centro, deve-se ao aumento da evapotranspiração do espaço verde com o aumento da altura do sol acima do horizonte e incremento do fluxo de calor latente em detrimento do fluxo de calor sensível. A partir da metade da manhã $(9 \mathrm{~h})$ até os finais do dia ( $22 \mathrm{~h}$ ) o centro passou a ser o núcleo mais quente da cidade, altura em que PC passou ser o núcleo mais frio, vindo logo depois a INMET.

\subsubsection{Intensidade média e variabilidade}

O ritmo da variação intradiurna das diferenças médias de temperatura (Quadro IVa,b,c e Figura 3) mostrou-se similar ao das frequências de ocorrência das diferenças térmicas positivas, analisadas anteriormente, somente a partir da metade da manhã até o período noturno (8-20h).

A maior intensidade média da ilha de calor foi registrada para CC-INFRA de $3.6^{\circ} \mathrm{C}$ às $11 \mathrm{~h}$, o que era de esperar, posto que o centro vem se configurando como núcleo mais quente da cidade. Uma hora antes, às $10 \mathrm{~h}$, o INMET-INFRA acusou o valor médio mais baixo de $0.4^{\circ} \mathrm{C}$, uma vez que para PC-INFRA desde às $23 \mathrm{~h}$ até às $8 \mathrm{~h}$ perdurou valores acima dos $0.7^{\circ} \mathrm{C}$, atingindo o máximo de $0.9^{\circ} \mathrm{C}$ pela manhã (6h). No que pese às diferenças médias mínimas de temperatura, PC-INFRA se destacou pelo fato de no período de maior aquecimento (9-20h) registrar valores negativos, cujo máximo foi de $-3.2^{\circ} \mathrm{C}$ ocorrido às $14 \mathrm{~h}$. Período em que também o INMET-INFRA acusou valores negativos, embora menores, com o máximo às $20 \mathrm{~h}$ de $-1 \cdot 1^{\circ} \mathrm{C}$. Já para CC-INFRA, as diferenças de temperaturas mínimas não foram significativas, ao apresentar valores nulos nas primeiras horas da manhã (5h e $7 \mathrm{~h})$.

Os valores de desvio-padrão revelaram a complexidade que se reveste a variabilidade intradiurna dos contrastes térmicos entre cada par de estações comparadas. A começar pelo INMET- INFRA, em que os valores variaram durante as 24 horas entre $0.4^{\circ} \mathrm{C}(4 \mathrm{~h}$ e $23 \mathrm{~h})$ e $1.1^{\circ} \mathrm{C}(13 \mathrm{~h})$, situação que indica, em grande parte, a influência amenizadora dos corpos d'água sobre os contrastes topoclimáticos, bem como põe em evidência a atuação das circulações locais de origem térmica, notadamente às de brisa marítima. Na medida em que a influência do rio e mar é diminuída, a variabilidade térmica tende a se alterar, como é o caso da variação um pouco maior, correspondente ao par CC-INFRA de $0.4^{\circ} \mathrm{C}(2 \mathrm{~h})$ a $1.5^{\circ} \mathrm{C}(10 \mathrm{~h})$. O que poderá justificar a alta variabilidade térmica intradiurna do par PC-INFRA, de $2.2^{\circ} \mathrm{C}(10 \mathrm{~h})$ a $0.8^{\circ} \mathrm{C}$ (4h), será a proximidade do rio Sergipe, em uma área sobreelevada $(100 \mathrm{~m}) \mathrm{e}$, por isso, a receber mais interferências microclimáticas do espaço verde. 
Quadro IV

Aracaju - Parâmetros estatísticos de tendência central (média e mediana) e de dispersão (desvio-padrão) das séries horárias de diferenças de temperatura.

a) - $\triangle T$ INMET-INFRA

\begin{tabular}{|c|c|c|c|c|c|c|c|c|c|c|c|c|c|c|c|c|c|c|c|c|c|c|c|c|}
\hline $\begin{array}{c}\Delta \mathrm{T}\left({ }^{\circ} \mathrm{C}\right) \\
\text { INMET-INFRA }\end{array}$ & 0 & 1 & 2 & 3 & 4 & 5 & 6 & 7 & 8 & 9 & 10 & 11 & 12 & 13 & 14 & 15 & 16 & 17 & 18 & 19 & 20 & 21 & 22 & 23 \\
\hline Média & -0.4 & -0.4 & -0.3 & -0.3 & -0.3 & -0.3 & -0.2 & -0.3 & -0.1 & 0.1 & 0.4 & 0.2 & -0.2 & -0.4 & -0.4 & -0.5 & -0.7 & -0.7 & -0.9 & -1.0 & -1.1 & -0.9 & -0.7 & -0.6 \\
\hline Mediana & -0.4 & -0.3 & -0.3 & -0.3 & -0.3 & -0.3 & -0.3 & -0.3 & -0.1 & 0.1 & 0.4 & 0.2 & -0.2 & -0.3 & -0.4 & -0.5 & -0.6 & -0.7 & -0.8 & -1.1 & -1.1 & -0.8 & -0.8 & -0.7 \\
\hline Desv. Padrão & 0.7 & 0.6 & 0.8 & 0.5 & 0.4 & 0.6 & 0.7 & 0.6 & 0.9 & 0.8 & 0.9 & 0.8 & 0.7 & 1.1 & 0.9 & 1.0 & 0.8 & 0.8 & 0.8 & 0.5 & 0.7 & 0.6 & 0.5 & 0.4 \\
\hline \multicolumn{25}{|c|}{ b) - $\Delta T$ CC-INFRA. } \\
\hline $\begin{array}{c}\Delta \mathrm{T}\left({ }^{\circ} \mathrm{C}\right) \\
\text { CC-INFRA }\end{array}$ & 0 & 1 & 2 & 3 & 4 & 5 & 6 & 7 & 8 & 9 & 10 & 11 & 12 & 13 & 14 & 15 & 16 & 17 & 18 & 19 & 20 & 21 & 22 & 23 \\
\hline Média & 0.4 & 0.3 & 0.4 & 0.3 & 0.2 & 0.0 & 0.2 & 0.0 & 0.1 & 1.1 & 3.4 & 3.6 & 3.0 & 3.2 & 2.9 & 2.7 & 2.7 & 2.7 & 2.4 & 2.0 & 0.7 & 0.3 & 0.5 & 0.6 \\
\hline Mediana & 0.6 & 0.4 & 0.4 & 0.2 & 0.1 & -0.1 & 0.2 & 0.2 & 0.4 & 1.3 & 3.4 & 3.5 & 3.1 & 3.3 & 2.9 & 2.6 & 2.6 & 2.7 & 2.4 & 2.0 & 0.7 & 0.4 & 0.4 & 0.6 \\
\hline Desv. Padrão & 0.6 & 0.5 & 0.4 & 0.5 & 0.5 & 0.6 & 0.6 & 0.9 & 1.0 & 1.0 & 1.5 & 1.3 & 1.1 & 1.0 & 1.1 & 0.8 & 0.8 & 1.3 & 1.2 & 0.7 & 0.7 & 0.8 & 0.5 & 0.6 \\
\hline
\end{tabular}

c) - $\triangle T$ PC-INFRA.

\begin{tabular}{|c|c|c|c|c|c|c|c|c|c|c|c|c|c|c|c|c|c|c|c|c|c|c|c|c|}
\hline $\begin{array}{c}\Delta \mathrm{T}\left({ }^{\circ} \mathrm{C}\right) \\
\text { PC-INFRA }\end{array}$ & 0 & 1 & 2 & 3 & 4 & 5 & 6 & 7 & 8 & 9 & 10 & 11 & 12 & 13 & 14 & 15 & 16 & 17 & 18 & 19 & 20 & 21 & 22 & 23 \\
\hline Média & 0.7 & 0.7 & 0.8 & 0.8 & 0.8 & 0.8 & 0.9 & 0.5 & 0.3 & -0.2 & -1.0 & -1.8 & -2.9 & -3.5 & -3.2 & -3.1 & -2.7 & -2.1 & -1.4 & -0.8 & -0.3 & 0.3 & 0.6 & 0.7 \\
\hline Mediana & 0.7 & 0.6 & 0.8 & 0.8 & 0.8 & 0.7 & 0.8 & 0.4 & 0.4 & 0.3 & -0.4 & -1.6 & -3.0 & -3.7 & -3.4 & -2.9 & -2.1 & -1.8 & -1.1 & -0.4 & 0.2 & 0.5 & 0.7 & 0.7 \\
\hline Desv. Padrão & 0.9 & 1.0 & 1.0 & 0.9 & 0.8 & 1.0 & 1.1 & 1.1 & 1.5 & 1.9 & 2.2 & 2.0 & 1.5 & 1.5 & 1.7 & 1.8 & 2.0 & 2.2 & 2.0 & 1.6 & 1.7 & 1.4 & 1.3 & 1.2 \\
\hline
\end{tabular}

Fonte: Observações em campo (CC e PC), INMET e INFRAERO.

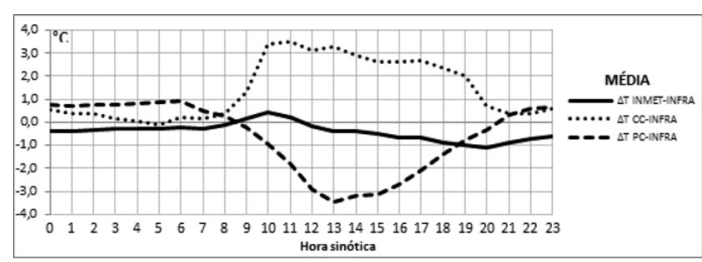

Figura 3

Aracaju - Variação intradiurna das diferenças médias de temperatura $(\Delta$ Tmed).

Fonte: Observações em campo (CC e PC), INMET e INFRAERO.

\subsubsection{Intensidade extrema}

Durante o final do dia $(22-23 \mathrm{~h})$ e toda madrugada (0-6h) ocorreram as maiores diferenças extremas positivas de temperatura para PC-INFRA variando entre $3.3^{\circ} \mathrm{C}$ a $3.9^{\circ} \mathrm{C}$, com máximo de $4.2^{\circ} \mathrm{C}$ às $6 \mathrm{~h}$ (Figura 4), altura em que CC-INFRA e INMET-INFRA não ultrapassaram os $2.0^{\circ} \mathrm{C}$ e $3.0^{\circ} \mathrm{C}$, respectivamente. Esse último valor do INMET-INFRA não está longe do seu máximo de $3.7^{\circ} \mathrm{C}$, que ocorreu um pouco mais tarde, início da manhã $(9 \mathrm{~h})$, tendo no conjunto dos pares comparados, a menor variabilidade térmica, como vista anteriormente.

Por outro lado, CC-INFRA se destacou além da maior variabilidade térmica extrema, com o máximo extremo de $7.5^{\circ} \mathrm{C}$ às $14 \mathrm{~h}$. Assim, foi durante o período entre as $10 \mathrm{~h}$ e as $19 \mathrm{~h}$ que a cidade experimentou os maiores extremos que, por sua vez, recaíram sobre o período de maior aquecimento devido à ocupação urbana do espaço. É nesse período entre $10 \mathrm{~h}$ às $19 \mathrm{~h}$ que se observam os maiores valores de diferenças térmicas negativas mínimas, com significativo destaque para PC-INFRA sempre acima dos $-5.0^{\circ} \mathrm{C}$ e máximo mínimo em dois momentos de $-6.5^{\circ} \mathrm{C}$ (13h e 15h). Em seguida, tem-se INMET-INFRA que apresentou uma sequência de valores abaixo dos $5.7^{\circ} \mathrm{C}$ muito variados ao longo do dia, enquanto para CC-INFRA, recaiu os menores valores, abaixo dos $-1.5^{\circ} \mathrm{C}$, agora um pouco mais perceptível no período referendado $(10-19 \mathrm{~h})$, sendo o maior valor $\left(-2.8^{\circ} \mathrm{C}\right)$ ocorrido pela manhã (8h).

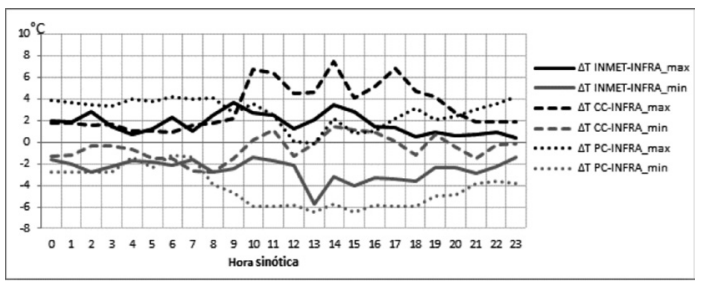

Figura 4

Aracaju - Variação intradiurna das diferenças extremas máximas e extremas mínimas de temperatura.

Fonte: Observações em campo (CC e PC), INMET e INFRAERO.

\subsubsection{Taxa de aquecimento e resfriamento horário}

Ao se tratar das taxas de aquecimento e resfriamento dos ritmos intradiurnos de diferenças 
médias de temperatura para cada estação meteorológica, os resultados na Figura 5 traduzem, de forma muito clara, o balanço radiativo e energético defasado e, por vezes, oposto em muitas áreas da cidade, pelo menos naquelas circundantes das estações consideradas. Tendo como causa principal, a maior inércia térmica do espaço construído e com maiores índices de ocupação do solo em comparação com os espaços não urbanos e com menores valores de sky view factor. Nesse sentido, a partir das $18 \mathrm{~h}$, o centro da cidade (CC) experimentou o início do resfriamento, um pouco mais tarde $(17 \mathrm{~h})$, do que noutra área urbana (INMET) e a periferia (INFRA). Esse efeito pode ser visualizado por uma inversão do sinal das diferenças entre as estações referidas, que se tornam negativas nos horários referidos. Dessa forma, observou-se o maior resfriamento inter-horário para CC com variação entre $-0.5^{\circ} \mathrm{C}(18 \mathrm{~h})$ e $-0.9^{\circ} \mathrm{C}(21 \mathrm{~h})$, atingindo o seu máximo de $-1.8^{\circ} \mathrm{C}$ às $20 \mathrm{~h}$, mesma hora em que INMET registrou também a sua maior taxa de resfriamento, embora bem menor com $-0.6^{\circ} \mathrm{C}$ e uma hora depois (22h) INFRA com o mesmo valor.

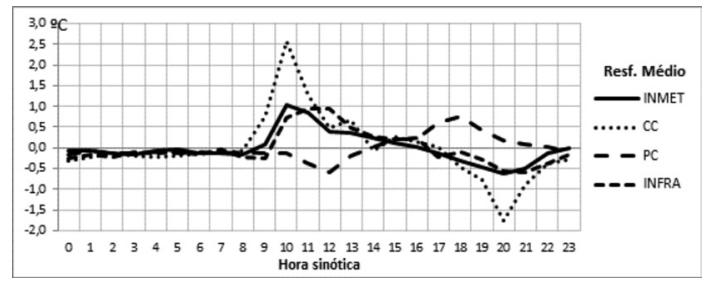

Figura 5

Aracaju - Variação intradiurna das taxas médias de aquecimento e/ou resfriamento horário (Resf. Médio).

Fonte: Observações em campo (CC e PC), INMET e INFRAERO.

Esse comportamento não se verifica para a estação representativa do espaço verde (PC) que, opostamente às demais, iniciou seu resfriamento durante a madrugada com taxas por volta dos $-0.2^{\circ} \mathrm{C}$ e se estendendo até a manhã com $-0.4^{\circ} \mathrm{C}$ às $11 \mathrm{~h} \mathrm{e}$ $-0.6^{\circ} \mathrm{C}$ às $12 \mathrm{~h}$. Momento no qual as estações representativas do espaço urbanizado (CC e INMET) e da periferia (INFRA) registraram acentuado aquecimento, embora com taxas diferentes entre si. Justamente, no período noturno, quando as estações referidas entram em processo de resfriamento, a PC registrou o seu período de aquecimento com a maior taxa de $0.8^{\circ} \mathrm{C}$ no início da noite $(18 \mathrm{~h})$, decaindo logo em seguida até a madrugada. Esse facto, pode ter a ver com a intervenção de factores locais no balanço energético do PC, tais como a advecção, porém, de difícil explicação com os dados disponíveis.

$\mathrm{Na}$ madrugada (0-5h) e às primeiras horas da manhã (6 e 7h) as taxas de resfriamento inter-horário foram praticamente irrelevantes, variando entre $-0.1^{\circ} \mathrm{C}$ a $-0.3^{\circ} \mathrm{C}$ por hora no conjunto das estações, isso devido à elevada umidade relativa do ar.

O início do aquecimento diurno, em particular, encontrou-se defasado no tempo apenas para as estações CC, INMET e INFRA, até porque, como visto, a PC nesse horário está a registrar, ainda, seu resfriamento. $\mathrm{O}$ aquecimento da $\mathrm{CC}$ começou mais cedo às
$8 \mathrm{~h}$ visto ser uma área comercial e serviços, atingindo seu pico duas horas depois. As taxas elevadíssimas de aquecimento da respectiva estação traduzem-se em diferenças positivas de temperatura relativamente à periferia e às demais áreas da cidade, que se verifica durante esse período. Com taxas menores à CC, a INMET inicia seu aquecimento às $9 \mathrm{~h}$ e máximo às $10 \mathrm{~h}$ prolongando-se gradualmente pela tarde, enquanto a INFRA inicia às $10 \mathrm{~h}$ com máximo às $12 \mathrm{~h}$.

\subsection{Análise comportamental da umidade relativa}

\subsubsection{Unidade relativa mínima diária}

Comparativamente aos parâmetros que definiram os contrastes térmicos a partir das diferenças de temperaturas, os de umidade relativa corroboram para evidenciar acentuados contrastes higrométricos superiores àqueles, no que tange aos valores mínimos diários de umidade relativa para o conjunto de 66 dias de observação (30 dias no caso da CC) (Quadro V).

Quadro V

Aracaju - Parâmetros estatísticos (tendência central, dispersão, extremos e frequência de ocorrência de valores positivos e nulos ou negativos) das séries horárias de diferenças de umidade relativa mínima ( $\Delta$ umin.)

\begin{tabular}{|c|c|c|c|}
\hline \multirow{2}{*}{} & \multicolumn{3}{|c|}{$\Delta U(\%)$} \\
\cline { 2 - 4 } & INMET-INFRA & CC-INFRA & PC-INFRA \\
\hline Média & 4.6 & -2.4 & 2.7 \\
\hline Mediana & 4 & -3 & 1 \\
\hline Desv. Padrão & 5.7 & 7.3 & 11.1 \\
\hline Máximo & 31 & 28 & 42 \\
\hline Mínimo & -9 & -12 & -47 \\
\hline$\% \geq 0$ & 87.9 & 22.2 & 59.1 \\
\hline$\%<0$ & 12.1 & 77.8 & 40.9 \\
\hline
\end{tabular}

Fonte: Observações em campo (CC e PC), INMET e INFRAERO.

Os valores da média foram significativamente diversos entre pares de estações analisadas: as diferenças foram positivas para INMET-INFRA (5 \%) e PC-INFRA (3\%), e negativas para CC-INFRA (-2\%), enquanto a mediana foi menor para os dois primeiros pares e maior para o último par. Já os valores do desvio-padrão conferiram para PC-INFRA a maior variabilidade interdiurna $(11 \%)$, quase o dobro do CC-INFRA (7\%) e quase o triplo da INMET-INFRA (5\%), igualmente para os valores extremos máximos e mínimos. Para PC-INFRA, a diferença positiva encontrada foi $42 \%$, seguido por INMET-INFRA com $31 \%$ e CC-INFRA com $28 \%$ e diferença mínima mais ainda significativa de $-47 \%$, $-9 \%$ e $-12 \%$ respectivamente.

Partindo do pressuposto da importância relativa de que se revestem os contrastes negativos $(\%<0)$ como indicativo de ilha de secura, de certo que o centro da cidade (CC-INFRA) está $77.8 \%$ de todo segmento temporal da investigação sob domínio deste fenômeno, contra $40.9 \%$ do PC-INFRA e $12.1 \%$ do INMET-INFRA. Esse último valor da INMET-INFRA está ligado à influência direta do estuário do rio Sergipe, predominando aqui $(83.3 \% \geq 0)$ situações de ilha de umidade, no que diz respeito aos valores mínimos diários de umidade relativa. 


\subsubsection{Comportamento intradiurno}

\subsubsection{Frequência de ocorrência}

O comportamento intradiurno da ilha de secura pode ser verificado nas frequências de ocorrência de valores horários negativos de diferenças de umidade relativa (Quadro VI e Figura 6) e, complementariamente, o da ilha de umidade expresso pelas frequências de ocorrência de valores nulos ou positivos de diferenças de umidade relativa (Quadro VII). Neste caso, notaram-se, a priori, para INMET-INFRA, frequências ao longo do dia superando $50 \%$, exceto às $10 \mathrm{~h}$ e, durante a tarde e noite $(13-22 \mathrm{~h})$, com mais de $80 \%$, o que evidenciou, estatisticamente, o caráter semi-permanente da ilha de umidade relativamente ao espaço periurbano da cidade.

A ocorrência da ilha de secura, por sua vez, pode ser mais sentida entre o final da manhã (10h) até a metade da noite $(19 \mathrm{~h})$ no centro da cidade (CC), onde se observaram valores superiores a $80 \%$ naturalmente no período de maior aquecimento relativamente à zona periférica (INFRA).

Durante a madrugada e inicio da manhã $(0-7 \mathrm{~h})$ as frequências se estabilizam, porém com valores inferiores entre os pares analisados: para CC-INFRA não ultrapassaram os $25 \%$, com percentual maior de $32 \%$ para INMET-INFRA e para PC-INFRA de $50 \%$.

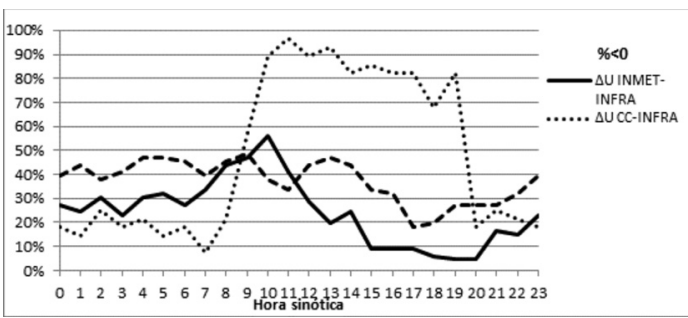

Figura 6

Aracaju - Variação intradiurna da frequência de ocorrência de diferenças de umidade relativa inferior a $0 \%(\Delta<0 \%)$.

Fonte: Observações em campo (CC e PC), INMET e INFRAERO.

\subsubsection{Intensidade média e variabilidade}

A intensidade média da ilha de secura no decorrer da madrugada (0-5h) não variou muito entre os pares de estações analisadas, de $-0.4 \%$ para PC-INFRA, passando por $1.7 \%$ para INMET-INFRA até os 2.7\% para CC-INFRA (Quadros VIII a,b,c e Figura 7). Uma hora depois (6h) já foi perceptível a diferença da CC-INFRA para as demais, sobretudo às $7 \mathrm{~h}$, quando registrou o maior valor $(4.1 \%)$. Porém, mesmo durante parte da manhã assistiu-se a um decréscimo, por via abrupto, nos valores de CC-INFRA a ponto de caracterizar forte magnitude de ilha de secura no centro da cidade em relação não só à periferia, mas também às áreas representadas pelas outras estações.

Quadro VI

Aracaju - Frequência de ocorrência de valores negativos das séries horárias de diferenças de umidade relativa $\triangle \mathrm{U}$ INMET-INFRA, $\triangle \mathrm{U}$ CC-INFRA, $\triangle \mathrm{U}$ PC-INFRA.

\begin{tabular}{|c|c|c|c|c|c|c|c|c|c|c|c|c|c|c|c|c|c|c|c|c|c|c|c|c|}
\hline$\%<0$ & 0 & 1 & 2 & 3 & 4 & 5 & 6 & 7 & 8 & 9 & 10 & 11 & 12 & 13 & 14 & 15 & 16 & 17 & 18 & 19 & 20 & 21 & 22 & 23 \\
\hline $\begin{array}{l}\Delta \mathrm{U}(\%) \\
\text { INMET- } \\
\text {-INFRA }\end{array}$ & 27.3 & 24.2 & 30.3 & 22.7 & 30.3 & 31.8 & 27.3 & 33.3 & 43.9 & 47.0 & 56.1 & 40.9 & 28.8 & 19.7 & 24.2 & 9.1 & 9.1 & 9.1 & 6.1 & 4.5 & 4.5 & 16.7 & 15.2 & 22.7 \\
\hline $\begin{array}{c}\Delta U(\%) \\
C C- \\
\text {-INFRA }\end{array}$ & 17.9 & 14.3 & 25.0 & 17.9 & 21.4 & 14.3 & 17.9 & 7.1 & 21.4 & 57.1 & 89.3 & 96.4 & 89.3 & 92.9 & 82.1 & 85.7 & 82.1 & 82.1 & 67.9 & 82.1 & 17.9 & 25.0 & 21.4 & 17.9 \\
\hline $\begin{array}{c}\Delta U(\%) \\
\text { PC- } \\
\text {-INFRA }\end{array}$ & 39.4 & 43.9 & 37.9 & 40.9 & 47.0 & 47.0 & 45.5 & 39.4 & 45.5 & 48.5 & 37.9 & 33.3 & 43.9 & 47.0 & 43.9 & 33.3 & 31.8 & 18.2 & 19.7 & 27.3 & 27.3 & 27.3 & 31.8 & 39.4 \\
\hline
\end{tabular}

Fonte: Observações em campo (CC e PC), INMET e INFRAERO.

Quadro VII

Aracaju - Frequência de ocorrência de valores nulos ou positivos das séries horárias de diferenças de umidade relativa $\triangle \mathrm{U}$ INMET-INFRA, $\triangle \mathrm{U}$ CC-INFRA, $\triangle \mathrm{U}$ PC-INFRA.

\begin{tabular}{|c|c|c|c|c|c|c|c|c|c|c|c|c|c|c|c|c|c|c|c|c|c|c|c|c|}
\hline$\% \geq 0$ & 0 & 1 & 2 & 3 & 4 & 5 & 6 & 7 & 8 & 9 & 10 & 11 & 12 & 13 & 14 & 15 & 16 & 17 & 18 & 19 & 20 & 21 & 22 & 23 \\
\hline $\begin{array}{c}\Delta \mathrm{U}(\%) \\
\text { INMET- } \\
\text {-INFRA }\end{array}$ & 72.7 & 75.8 & 69.7 & 77.3 & 69.7 & 68.2 & 72.7 & 66.7 & 56.1 & 53.0 & 43.9 & 59.1 & 71.2 & 80.3 & 75.8 & 90.9 & 90.9 & 90.9 & 93.9 & 95.5 & 95.5 & 83.3 & 84.8 & 77.3 \\
\hline $\begin{array}{c}\Delta \mathrm{U}(\%) \\
\text { CC-INFRA }\end{array}$ & 82.1 & 85.7 & 75.0 & 82.1 & 78.6 & 85.7 & 82.1 & 92.9 & 78.6 & 42.9 & 10.7 & 3.6 & 10.7 & 7.1 & 17.9 & 14.3 & 17.9 & 17.9 & 32.1 & 17.9 & 82.1 & 75.0 & 78.6 & 82.1 \\
\hline $\begin{array}{c}\Delta U(\%) \\
\text { PC-INFRA }\end{array}$ & 60.6 & 56.1 & 62.1 & 59.1 & 53.0 & 53.0 & 54.5 & 60.6 & 54.5 & 51.5 & 62.1 & 66.7 & 56.1 & 53.0 & 56.1 & 66.7 & 68.2 & 81.8 & 80.3 & 72.7 & 72.7 & 72.7 & 68.2 & 60.6 \\
\hline
\end{tabular}


Esse acentuado contraste higrométrico espacial se prolonga até parte da noite $(20 \mathrm{~h})$. A mediana se encontra defasada ao longo do dia para todos os pares, intercalando valores acima, iguais ou abaixo da média.

Em termos de variabilidade higrométrica expressa nos valores de desvio-padrão, deve-se a INMET-INFRA o caráter mais regular durante todo o dia, cuja variação ficou entre $2.8 \%$ às $19 \mathrm{~h}$ e $5.9 \%$ às $8 \mathrm{~h}$. No caso do CC-INFRA a variabilidade higrométrica se mostrou mais marcada, principalmente na amplitude dos valores, sendo os maiores (6.9\%) ocorridos na metade da manhã (10h) e início da noite $(18 \mathrm{~h})$, período já caracterizado por fortes contrastes tanto higrométricos quanto térmicos, enquanto os menores valores $(2.5 \%)$ ocorreram durante os finais da noite $(19 \mathrm{~h})$ estendendo-se pela madrugada (0-5h).

Mas PC-INFRA se destacou com valores que chegaram a rondar os $7.7 \%$ a $9.5 \%$ em muitos momentos do dia, com uma ligeira tendência a ocorrerem mais nos final da manhã (10h) e durante a tarde $(14 \mathrm{~h})$, por ser o período em que o Parque da Cidade experimentou os mais baixos contrastes térmicos.

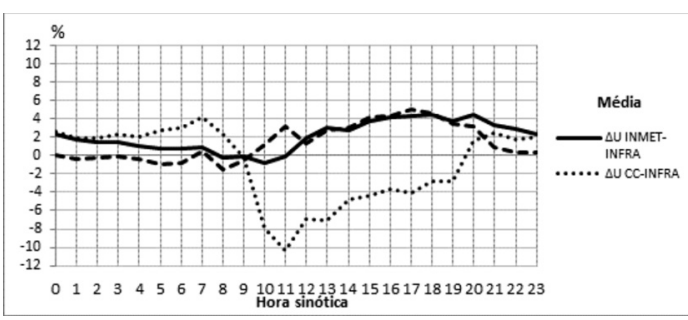

Figura 7

Aracaju - Variação intradiurna das diferenças médias de umidade relativa ( $\Delta$ Umed).

Fonte: Observações em campo (CC e PC), INMET e INFRAERO.

\subsubsection{Intensidade extrema}

A análise dos extremos máximos e mínimos das séries horárias de diferenças de umidade relativa INMET-INFRA, CC-INFRA e PC-INFRA corroborou a existência de significativos contrastes higrométricos em Aracaju no decorrer do dia (Figura 8).

Durante o dia os extremos máximos concorrem para certa homogeneidade para INMET-INFRA e PC-

\section{Quadro VIII}

Aracaju - Parâmetros estatísticos de tendência central (média e mediana) e de dispersão (desvio-padrão) das séries horárias de diferenças de umidade relativa.

a) - $\triangle U$ INMET-INFRA.

\begin{tabular}{|c|c|c|c|c|c|c|c|c|c|c|c|c|c|c|c|c|c|c|c|c|c|c|c|c|}
\hline $\begin{array}{c}\Delta \mathrm{U}(\%) \\
\text { INMET-INFRA }\end{array}$ & 0 & 1 & 2 & 3 & 4 & 5 & 6 & 7 & 8 & 9 & 10 & 11 & 12 & 13 & 14 & 15 & 16 & 17 & 18 & 19 & 20 & 21 & 22 & 23 \\
\hline Média & 2.3 & 1.7 & 1.5 & 1.4 & 1.1 & 0.7 & 0.8 & 0.9 & -0.3 & -0.1 & -0.8 & -0.2 & 1.9 & 3.1 & 2.7 & 3.8 & 4.2 & 4.4 & 4.4 & 3.7 & 4.5 & 3.3 & 3.0 & 2.4 \\
\hline Mediana & 2.5 & 1.0 & 1.0 & 2.0 & 1.0 & 1.0 & 1.0 & 1.0 & 1.0 & 0.0 & -1.0 & 0.5 & 2.0 & 3.0 & 3.0 & 4.0 & 4.0 & 5.0 & 4.0 & 3.0 & 4.0 & 4.0 & 3.0 & 3.0 \\
\hline Desv. Padrão & 5.2 & 4.9 & 4.6 & 3.4 & 3.3 & 3.4 & 4.3 & 3.6 & 5.9 & 4.4 & 5.1 & 4.6 & 4.3 & 4.7 & 4.9 & 5.1 & 3.7 & 3.9 & 4.0 & 2.8 & 3.4 & 5.0 & 4.5 & 5.5 \\
\hline
\end{tabular}

b) - $\triangle U$ CC-INFRA.

\begin{tabular}{|c|c|c|c|c|c|c|c|c|c|c|c|c|c|c|c|c|c|c|c|c|c|c|c|c|}
\hline $\begin{array}{c}\Delta U(\%) \\
\text { CC-INFRA }\end{array}$ & 0 & 1 & 2 & 3 & 4 & 5 & 6 & 7 & 8 & 9 & 10 & 11 & 12 & 13 & 14 & 15 & 16 & 17 & 18 & 19 & 20 & 21 & 22 & 23 \\
\hline Média & 2.6 & 1.9 & 1.9 & 2.4 & 2.1 & 2.7 & 3.0 & 4.1 & 2.4 & -0.3 & -7.9 & -10.4 & -7.0 & -7.0 & -4.8 & -4.3 & -3.7 & -4.1 & -2.8 & -2.8 & 1.7 & 2.5 & 1.8 & 2.1 \\
\hline Mediana & 3.0 & 2.0 & 2.0 & 2.5 & 3.0 & 3.0 & 2.5 & 4.0 & 3.0 & -1.0 & -6.5 & -9.5 & -7.0 & -7.0 & -4.5 & -3.5 & -3.0 & -3.0 & -2.5 & -3.0 & 2.0 & 4.0 & 2.0 & 2.5 \\
\hline $\begin{array}{l}\text { Desv. } \\
\text { Padrão }\end{array}$ & 3.6 & 2.8 & 3.4 & 3.3 & 3.3 & 3.9 & 3.7 & 3.7 & 7.2 & 6.1 & 6.9 & 6.5 & 5.1 & 4.6 & 5.4 & 4.5 & 4.4 & 4.9 & 6.5 & 2.5 & 3.6 & 5.2 & 3.5 & 4.3 \\
\hline
\end{tabular}

c) - $\triangle U$ PC-INFRA.

\begin{tabular}{|c|c|c|c|c|c|c|c|c|c|c|c|c|c|c|c|c|c|c|c|c|c|c|c|c|}
\hline $\begin{array}{c}\Delta U(\%) \\
\text { PC-INFRA }\end{array}$ & 0 & 1 & 2 & 3 & 4 & 5 & 6 & 7 & 8 & 9 & 10 & 11 & 12 & 13 & 14 & 15 & 16 & 17 & 18 & 19 & 20 & 21 & 22 & 23 \\
\hline Média & 0.1 & -0.4 & -0.3 & -0.1 & -0.3 & -1.0 & -0.8 & 0.4 & -1.5 & -0.5 & 1.2 & 3.2 & 1.4 & 2.8 & 3.1 & 4.2 & 4.3 & 5.1 & 4.7 & 3.4 & 3.1 & 1.0 & 0.3 & 0.3 \\
\hline Mediana & 1.0 & 0.0 & 0.5 & 0.0 & 0.0 & 0.0 & 0.0 & 1.0 & 0.0 & 0.0 & 1.0 & 4.0 & 0.0 & 1.5 & 2.0 & 4.0 & 4.0 & 4.5 & 4.5 & 3.0 & 3.5 & 2.0 & 2.0 & 1.0 \\
\hline $\begin{array}{l}\text { Desv. } \\
\text { Padrão }\end{array}$ & 5.7 & 5.4 & 4.9 & 4.8 & 5.0 & 5.9 & 6.3 & 5.4 & 8.2 & 7.7 & 7.7 & 8.0 & 9.4 & 8.9 & 9.5 & 9.0 & 8.4 & 7.6 & 6.9 & 6.2 & 6.0 & 6.2 & 5.9 & 5.5 \\
\hline
\end{tabular}


-INFRA, embora que no período da tarde PC-INFRA acusou um ligeiro aumento, em contrapartida, o CC-INFRA se apresentou durante a madrugada com valores abaixo dos $10 \%$, atingindo seus máximos (19\%) no princípio da manhã, posteriormente os valores desceram a patamares inferiores aos demais pares, prolongando-se até os finais da noite.

No caso dos extremos mínimos, a homogeneidade se inverte entre os pares, agora para PC-INFRA e CC-INFRA a partir das $10 \mathrm{~h}$, porque na madrugada os valores se apresentaram bem diferentes entre si: sendo maiores para PC-INFRA (-22\%), seguido pelo INMET-INFRA $(-16 \%)$ e último o CC-INFRA (-9\%). Mas em toda tarde e noite, o INMET-INFRA se destacou entre aqueles com os menores extremos mínimos.

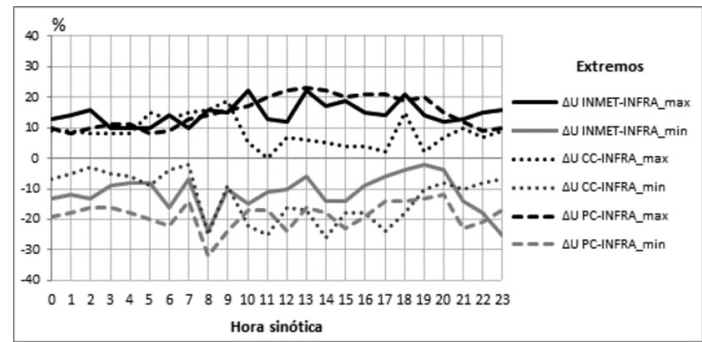

Figura 8

Aracaju - Variação intradiurna das diferenças extremas máximas e extremas mínimas de umidade relativa.

Fonte: Observações em campo (CC e PC), INMET e INFRAERO.

\section{Notas conclusivas}

Este trabalho encontrou evidências significativas de contrastes topoclimáticos no espaço intraurbano de Aracaju, o que leva a fortes indícios de ocorrência da ilha de calor. Isto foi possível mediante o confronto dos dados de temperatura e umidade relativa entre as estações meteorológicas do Parque da Cidade (PC), do Centro da Cidade (CC) e do Instituto Nacional de Meteorologia (INMET) com a estação meteorológica da INFRAERO (INFRA) localizada no Aeroporto de Santa Maria, de caráter mais periurbano.

Durante o segmento temporal da investigação de 66 dias de observação, exceto para a CC que foi de 30 dias, tornou-se notório a diferença térmica e higrométrica entre a própria área urbana e em relação à área periurbana de Aracaju. 0 centro da cidade se destaca com temperaturas mais elevadas do que a periferia da cidade onde podem ser verificadas com mais clareza nos valores das frequências relativas de ocorrência de diferenças de temperatura máxima maiores que zero $(\%>0)$. Tais frequências superaram os $96 \%$ em que a temperatura do centro da cidade foi superior ao do espaço periurbano, corroborando assim, a existência e incidência de ilha de calor.

A ilha de calor em seu ritmo intradiurno foi mais intenso para o par CC-INFRA, em que os valores das $\%>0$ situaram-se por volta dos $100 \%$ durante os finais da manhã $(9 \mathrm{~h})$ até parte da noite $(22 \mathrm{~h})$, isto é, momento em que o centro se tornou o núcleo mais quente da cidade. Em contrapartida, o núcleo mais quente durante o final da noite, madrugada até o início da manhã (23-8h) passou a ser PC-INFRA, nos quais os valores foram superiores a $50 \%$, porque no período curto da manhã (9-11h) foi quando o INMET-INFRA ultrapassou os $50 \%$ e tornou-se o mais quente. Seguidamente a intensidade extrema correspondeu com expectativas quando registrou valores máximos de $7.5^{\circ} \mathrm{C}$ às $14 \mathrm{~h}$ para o CC-INFRA, $4.2^{\circ} \mathrm{C}$ às $6 \mathrm{~h}$ para PC-INFRA e $3.7^{\circ} \mathrm{C}$ às $9 \mathrm{~h}$ para INMET-INFRA.

A análise do comportamento da umidade relativa comprovou a existência de significativos contrastes higrométricos em Aracaju. Mais especificamente, a frequência relativa das diferenças de umidade relativa mínima negativa ou menor que zero $(\%<0)$, o que corresponde mais fielmente a ilha de secura, colocou o centro da cidade sob domínio em $77.8 \%$ de casos sobre tal fenômeno em relação à periferia, seguido pelo Parque da Cidade com $40.9 \%$ e deixando as áreas representadas por INMET com a menor frequência de apenas $12.1 \%$. Este valor equivale dizer que a INMET permaneceu sob domínio de $87.9 \%$ de situações de ilha de umidade, ou seja, mais úmida (e fresca) que a periferia, atrelado à influência direta do estuário do rio Sergipe.

0 ritmo intradiurno a ilha de secura foi mais sentida no final da manhã $(10 \mathrm{~h})$ até metade da noite $(19 \mathrm{~h})$, quando o centro da cidade registrou frequências $(\%<0)$ que ultrapassaram os $80 \%$, altura em que, simultaneamente, acontecia o maior aquecimento em relação à periferia. Em compensação, o Parque da Cidade acusou valores rodando os $40 \%$, que por sinal foram maiores que às demais, durante a madrugada até a manhã $(0-8 \mathrm{~h})$.

Não menos importante, têm-se os condicionantes geoecológicos refletidos no uso e ocupação solo de Aracaju que, além de torná-la atrativa para temática abordada, desempenhou papel relevante nos resultados alcançados. Ao adentrar a cidade, percebeu-se como a mediocridade do relevo teve uma importância pouco significativa, na medida em que não exerceu fator influenciador nos contrastes topoclimáticos, mas ao mesmo tempo, constitui um espaço livre à penetração de vários sistemas atmosféricos de circulação regional e de circulação local, nomeadamente às de brisas, que têm um peso importante no comportamento topoclimático. A posição latitudinal (entre os trópicos) e litorânea é a sustentação inicial para um grande volume de energia no sistema clima urbano de Aracaju e para fortes índices de umidade relativa, respectivamente. A este último fator, agrega-se a existência de vários cursos de água que cortam a cidade e a vegetação luxuriante, que desempenham papel amortizador dos contrastes térmicos e higrométricos. Isto comprovado, nas áreas por eles ladeadas, por temperaturas menores e valor expressivo de umidade relativa, ao longo de todas as observações e pelo confronto entre as estações meteorológicas padrão com as urbanas.

A temática central do estudo chama a atenção para a necessidade de um conjunto aperfeiçoado de estações meteorológicas sobre e para o clima urbano de Aracaju. O banco de dados da estação padrão do 
Instituto Nacional de Meteorologia tem sido útil, quer por levar ao cidadão informações sobre o tempo meteorológico, quer como base de diversos estudos climatológicos de cunho regional, entre outros serviços importantes. A estação da INFRAERO restringe-se mais a observação e análise das condições meteorológicas do espaço aéreo e que, no presente estudo, também serviu de apoio pela característica periurbana de que é inerente. Mas o que estas estações meteorológicas têm em comum é a limitação em registrar as variadas condições meteorológicas a nível local e microclimático impostas pela densidade populacional e a crescente urbanização. Isso tem levado a incertezas na área de mudanças climáticas de escala local, em que os registros padecem de uma estrutura articulada de estações urbanas.

Nesse sentido, a fim de estudar o desenvolvimento do clima urbano de Aracaju, uma nova rede urbana de instrumentos meteorológicos devem ser tomados em consideração, a citar pela notável ausência de qualquer histórico de registros de temperatura e umidade relativa em áreas industriais, no centro da cidade ou em parques verdes. De fato, a maioria dos registros climáticos urbanos é recolhida a distâncias longínquas da ocorrência de ilha de calor ou ilha de secura urbana. Uma rede articulada de estações meteorológicas urbanas seria uma oportunidade para compreensão de vários fenômenos climáticos.

\section{Referências bibliográficas}

Anjos, M.; Ganho, N. e Araúso, H. (2014) - "Uma análise dos contrastes topoclimáticos no espaço urbano e periurbano de Aracajú/SE: os campos térmicos e higrométricos". Revista Brasileira de Climatologia, vol. 13, Associação Brasileira de Climatologia ABClima, Universidade Federal do Paraná, Curitiba/ PR, Brasil, pp. 298-318.

Ansos, M. W. B. (2012) - Ambiente Urbano: constrastes térmicos e higrométricos espaciais em Aracaju-Sergipe (Brasil). Dissertação de Mestrado em Geografia Física, Faculdade de Letras, Universidade de Coimbra, Coimbra.
ARNField A. J. (2003) - "Two decades of urban climate research: a review of turbulence, exchanges of energy and water, and the urban heat island". International Journal of Climatology, vol. 23, pp. 1-26.

IBGE, (2012) Instituto Brasileiro de Geografia e Estatística. Censo demográfico de 2010, Brasil.

Ganho, N. (1995) - "A ilha de calor de Coimbra: intensidade e ritmo diário - Resultados de observações com termohigrógrafos em abrigo". Actas do II Congresso da Geografia Portuguesa, Coimbra, pp. 197-209.

Ganho, N. (1998) - O Clima Urbano de Coimbra: estudo de climatologia local aplicada ao ordenamento urbano. Dissertação de Doutoramento em Geografia Física, Faculdade de Letras da Universidade de Coimbra, Coimbra.

Ganho, N. (1999) - "Clima Urbano e a Climatologia Urbana. Fundamentos e aplicação ao ordenamento urbano". Cadernos de Geografia, 18, pp. 97-127.

Ganho, N. (2000) - "Contrastes higrométricos entre o centro e a periferia urbana de Coimbra - Sentido, intensidade e ritmo diário". Cadernos de Geografia, 19, pp. 69-81.

Monteiro, C. A. F. (1990) - "Adentrar a cidade para tomar-lhe a temperatura”. Geosul, vol. 5, n 9, Florianópolis, pp. 61-79.

Nimer, E. (1971) - “Climatologia da Região Nordeste do Brasil. Introdução à Climatologia Dinâmica. Subsídios à Geografia Regional do Brasil". Revista Brasileira de Geografia. n 34, pp. 3-51.

OKE, T. R. (1982) - "The energetic basis of the urban heat island". Quarterly Journal of the Royal Meteorological Society, $\mathrm{n}^{\circ} 108$, pp. 1-24.

OKE, T. R. (1987) - Boundary Layer Climates. Routledge, London.

Ren, C.; Ng, E. e Katzschner, L., (2010) - "Urban climatic map studies: a review”. International Journal of Climatology. vol. $31 / \mathrm{n}^{\circ} 15$, pp. 2213-2233. 